\title{
Assessment of Geometric Accuracy of a 5-axis CNC Machine in the Context of Machining Aircraft Transmission Housings
}

\author{
Grzegorz Bomba ${ }^{1}$, Piotr Gierlak ${ }^{2, *}$ \\ ${ }^{1}$ Pratt \& Whitney Rzeszów S.A, 35-078 Rzeszów, Poland \\ ${ }^{2}$ Faculty of Mechanical Engineering and Aeronautics, Rzeszow University of Technology, 35-959 Rzeszów, Poland
}

\begin{abstract}
Cite This Paper in the following Citation Styles
(a): [1] Grzegorz Bomba, Piotr Gierlak, "Assessment of Geometric Accuracy of a 5-axis CNC Machine in the Context of Machining Aircraft Transmission Housings," Universal Journal of Mechanical Engineering, Vol. 8, No. 5, pp. 257-263, 2020. DOI: 10.13189/ujme.2020.080503.

(b): Grzegorz Bomba, Piotr Gierlak, (2020). Assessment of Geometric Accuracy of a 5-axis CNC Machine in the Context of Machining Aircraft Transmission Housings. Universal Journal of Mechanical Engineering, 8(5), 257-263. DOI: 10.13189/ujme.2020.080503.
\end{abstract}

Copyright $\odot 2020$ by authors, all rights reserved. Authors agree that this article remains permanently open access under the terms of the Creative Commons Attribution License 4.0 International License

\begin{abstract}
This article presents a procedure whose goal was to develop an effective methodology for deploying a 5-axis milling centre in industrial conditions. The method presented in the article, based on the manufacturing of the test piece, aims to reduce the time to deploy a new machine and minimize the effort put in by technological services and maintenance during tests and the process of deploying the machine tool in production. The test piece and its position have been designed in such a way that its manufacture forces the use of complex machine movements in the extreme area of the working space. The paper presents the results of tests involving the machining of a test piece on a CNC machine, measurement of the shape and dimensional characteristics of the object using CMM and analysis of machining accuracy in the context of the use of the machine in the production of aircraft transmission bodies. The material of the test piece is the same as the material of aircraft transmission housings, i.e. aluminum alloy. The universality of presented method is due to the fact that it is independent of the size of the machine's machining space, machine kinematics and also the special functions possessed by the machine; however, it gives a representation of their operation in the form of measuring sheets from the measuring laboratory.
\end{abstract}

Keywords CNC, Geometric Accuracy, Test Piece

\section{Introduction}

This article presents a procedure whose goal was to develop an effective methodology for deploying a 5-axis milling centre in industrial conditions. The method presented in the article aims to reduce the time to deploy a new machine and minimize the effort put in by technological services and maintenance during tests and the process of implementing the machine tool, with particular emphasis on the requirements of machining aircraft bodies.

In recent years in the aviation industry, where high precision of workpieces is required, one can observe a tendency to replace parts of technological lines by the use of 5-axis machining centres. Despite this, no standard has yet been developed for assessing the performance of these machine tools. When analysing the accuracy of the machine, many factors that change the accuracy of the test piece should be taken into account. These include, for example, incomplete information about the current state of the machine tool depending on the ambient temperature, degree of machine wear, coolant temperature, usage history (minor collisions, overloads, etc.) or seemingly trivial factors such as daylight in the hall (rays of sunlight falling on the machine body) and others.

The basic tests that the machine tool undergoes are: testing of linear positioning accuracy (laser test) [1], "ball bar" test [2] to determine the circularity accuracy, static accuracy test and finally a work test to determine the real effect of the machine's accuracy on a workpiece [1]. This last test, consisting of making a test piece $[3,4]$, can give the most reliable information about the accuracy of the machine and about the possibility of 
using it with the provided parts. It is important because it can be carried out in conditions as close to real life as possible. Therefore, making a test piece becomes a basic test of the geometric accuracy and precision of machine positioning. The method of using test pieces to indirectly assess the accuracy of machine tools is the subject of numerous publications. The shape and method of making test pieces depend on their use [5-9].

In order to properly design a test piece, the specificity of the parts ultimately made on the machine must be taken into account. In the analysed case these are aircraft transmission housings. Placement of bearing seats is one of the most important geometrical parameters of the gears. It has a direct impact on factors determining the lifetime of an aircraft transmission, such as [10]:

- changing the play of a pair of mating wheels,

- improper gearing of a pair of gears,

- slip velocity value,

- surface peeling (spalling),

- risk of teeth damage or breakage.

Each hole that is a bearing seat is machined by a number of cutting tools defined in the process, e.g. precision adjustable boring bars. Technological allowance is left for finishing boring ensuring minimal deformation of the workpiece caused by cutting forces during machining and at the same time guaranteeing that the required dimensional and shape features are obtained [11]. In order to minimize the value of seat position errors, they are machined sequentially with a machined object orientation unchanged relative to the machine spindle. In the case of aviation transmission, the kinematic chain of the transmission is built based on cylindrical gears. This results in the fact that the kinematic chain of the gear bearing seats can be machined using one work surface, e.g. the XY machine base plane. For more complex gears, after finishing all holes on one side of the workpiece, the housing rotates to the next position and the next group of holes is machined in the same way. Following the described machining method, it is assumed that the position of gear wheel bearing seats is mainly determined by the kinematic accuracy of the CNC machine [12]. On the other hand, the accuracy of the boring operation of the bearing seats largely determines the quality of the body and directly affects the quality of the entire aircraft transmission [11].

Chapter 2 presents the proposed test piece. It is significantly different from the standard sample [13]. The test piece presented in the article was designed as a test piece to certify the ability of the machine tool to make an aircraft transmission body, and in particular to obtain the position of bearing seats in accordance with the requirements. Chapter 3 describes the test method consisting in the manufacturing of technological samples and their measurement in laboratory conditions, and the results obtained are presented and discussed. Chapter 4 contains a summary of the work.

\section{Description of the test piece}

The design of the technological sample presented in the article was developed by the technological services of a plant from the aviation industry specializing in the production of aircraft engine components (Figure 1). It contains the design assumptions of the workpiece, machining technologies of the presented technological sample, using a 5-axis CNC machine, a plan for measuring the geometrical characteristics of the sample on a coordinate measuring machine (CMM) and a presentation of the interpretation of CMM measurement report results.

The test piece is made of an aluminium alloy cylindrical bar with diameter $\phi=140 \mathrm{~mm}$ according to AMS4342, on which 5 phase surfaces, three groups of test holes and two centric holes are milled in the machining process. An additional shelf was made along one of the linear axes, constituting the angular base for the CMM.

As indicated in the introduction, the purpose of machining on a technological sample is to obtain measurement data to provide guaranteed geometric accuracy of the analysed 5-axis CNC machine. The aim of the work was to design a test piece that can provide the maximum amount of necessary data, while ensuring ease of manufacturing and ease of measurement, and a relatively low cost of manufacturing.

Key information from the point of view of an airframe manufacturer is:

- flatness of the obtained surface in the machine XY plane, accuracy of the position of holes made from approaches with $\mathrm{X}$ and $\mathrm{Y}$ axes,

- accuracy of the position of holes made using a divider (rotary table - 5th axis C),

- accuracy of the position of holes located on inclined surfaces - related to the composition of the movements of all linear axes and the 4th axis $\mathrm{A}$ and the fifth axis $\mathrm{C}$,

- circular interpolation error in the XY base plane.

In order to meet the above requirements, mainly for the holes made, which for the final machined body are to testify to the accuracy of the position of bearing seats and base holes, the position of test holes for the test piece shown in Figure 2 has been proposed.

The holes shown in Figure 2 are divided into certain groups that decide on the kinematic method of their implementation and are also a premise for assessing the kinematic quality of the machine tool.

Holes 2.1 to 2.6 are a group of holes intended to testify to the geometric accuracy of the machine tool for making bearing seats. Such holes are made in the XY base plane, using only $\mathrm{X}$ and $\mathrm{Y}$ linear axes and the $\mathrm{Z}$ working axis. For the presented test piece they are evenly distributed in a circle with a given diameter and a given division.

Holes 3.1 to 3.5 are a group of holes that is ultimately intended to provide information about the hole position error resulting from a machine divider error. If the test piece was mounted so that its axis would be in the axis of rotation of the machine tool divider, then the machine would make only one set-up approach in the XY plane and working motion in the $\mathrm{Z}$ axis, and all other holes would be made only by table division and movement working in the $\mathrm{Z}$ axis. This technology of making holes is commonly used for precise drilling of holes, e.g. in ring wheels, or on circular flanges, where these holes form the assembly axis of the workpiece. Due to the fact that for the discussed case the test piece was mounted at a consider- 

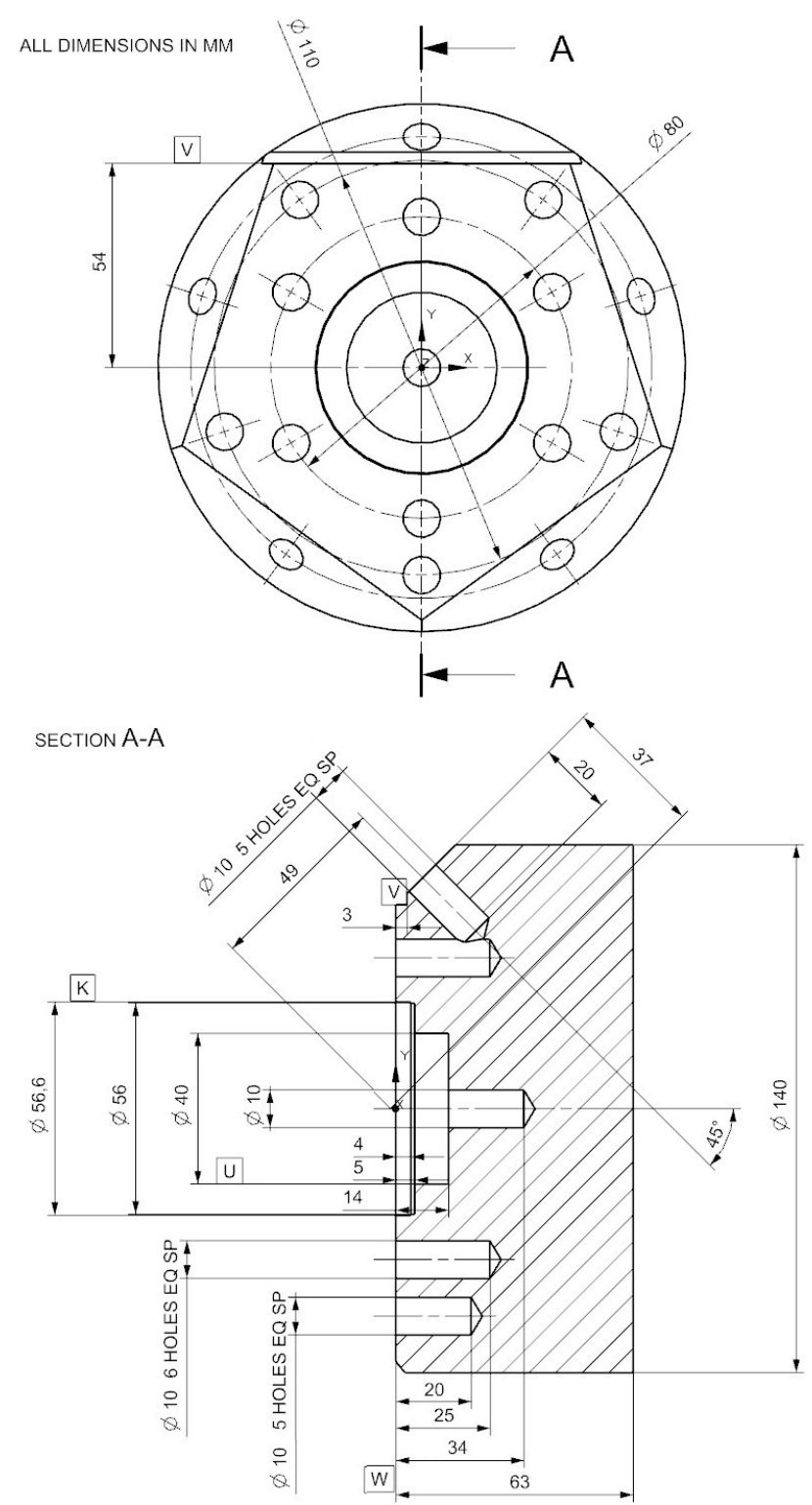

Figure 1. Test piece proposed to assess the geometric accuracy of the machine.

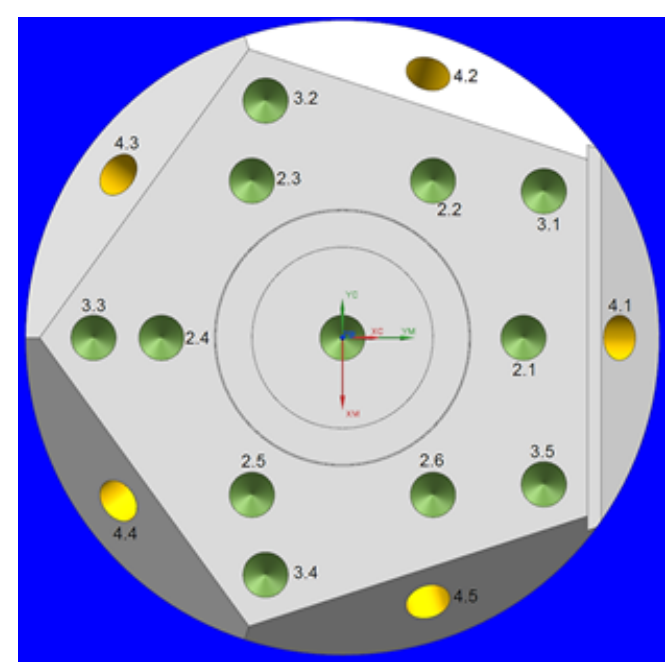

Figure 2. Position of test holes on the test piece. able distance from the axis of rotation of the table, to make this group of holes it is necessary to assemble the position of the $\mathrm{X}$ and $\mathrm{Y}$ linear axes and the table divider - $\mathrm{C}$ axis. This case is shown in Figure 3.
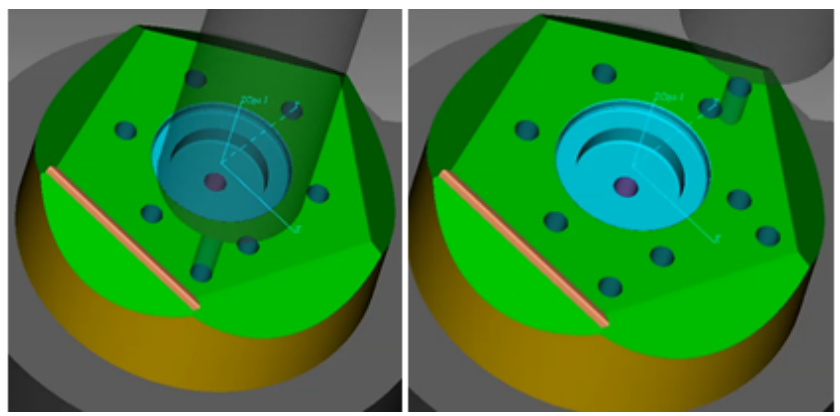

Figure 3. Simulation of drilling holes 3.1 (left drawing) and 3.3 (right drawing) in the Vericut environment.

This arrangement of the workpiece in relation to the axis of rotation of the table brings additional information. This includes a larger hole position error resulting from its much greater distance from the table axis. Thus, the error resulting from the positioning error of the divider itself has a much greater impact on the target position of the holes. It should be noted that the position errors of the resulting group of holes result from the division errors of the divider itself as well as from positioning errors of the $\mathrm{X}$ and $\mathrm{Y}$ axes. The machining centre for which the tests were conducted is a machine with increased accuracy of performance. The machining space of the machine is $1150 \mathrm{~mm}$ for the $\mathrm{Y}$ axis, $925 \mathrm{~mm}$ for the $\mathrm{X}$ axis and $550 \mathrm{~mm}$ for the $\mathrm{Z}$ axis, respectively. The range of rotary axes is $120 \mathrm{de}-$ grees for the cradle - A axis, and 360 degrees for the divider $\mathrm{C}$ axis, respectively. The machine is equipped with measuring rulers for each of the linear axes, and the positioning errors of each of the machine tool's linear axes do not exceed $\pm 2 \mu \mathrm{m}$. It can therefore be assumed that the positioning error of the $\mathrm{X}$ axis and the $\mathrm{Y}$ axis is constant and known, which has been confirmed by a separate, independent test using laser interference [14]. The positioning errors of the angular axes A and C are within \pm 0.001 degrees. The position of the angular axes is read by means of the $\mathrm{A}$ and $\mathrm{C}$ axis encoders. Therefore, the positioning error of the divider itself can be determined in relation to the position of the test piece on a given radius relative to the axis of machine $\mathrm{C}$ axis.

The hole group $4.1-4.5$ (located on the lateral phases) is made using all machine axes. The position of the test piece on the edge of the table provides information on so-called volumetric error being the diagonal of a cube whose sides are position errors in the $\mathrm{X}$ axis, $\mathrm{Y}$ axis and $\mathrm{Z}$ axis, respectively. The machine axis settings for the group 4 holes are shown in Figure 4.

For the test piece discussed in this article, the same inclination of all lateral phases, equal to 45 degrees, was assumed. Data was available from another test, not discussed here, regarding positioning error of the 4 th axis - cradle. This test clearly showed that this error is more or less the same throughout the entire range of the machine table inclination [14]. However, if this data was not available, it is easy to define phases 

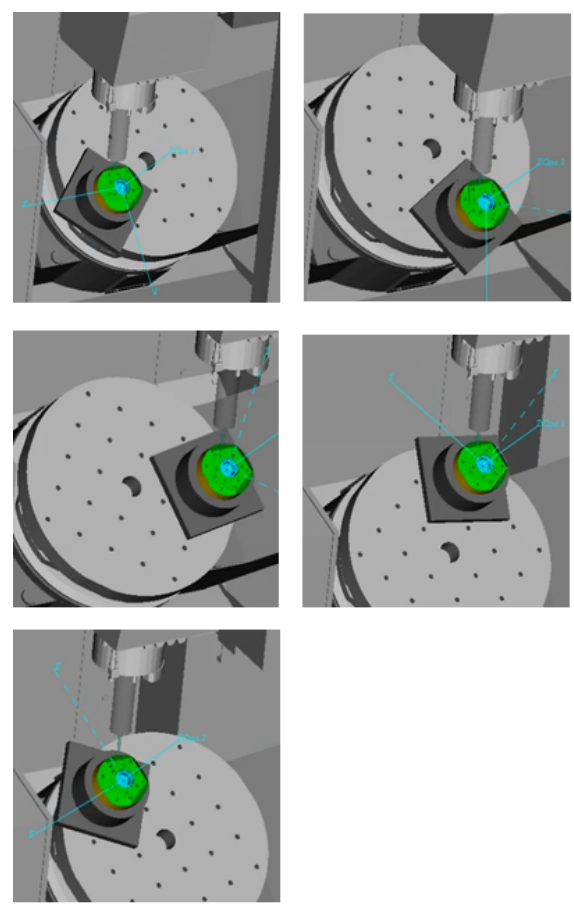

Figure 4. Simulation of drilling holes 4.1 - 4.5 in a Vericut environment.

with different inclination and constant gradient that would give a picture of the table inclination error within the required range. In addition, the machining program can be developed so that the holes on the phases are alternately drilled, once on the positive and once on the negative cradle inclinations.

In order to determine the machine error for circular interpolation, it was planned to drill a centric hole -K- in the sample. Detailed information is provided in chapter 3.

In addition, components are made on the machine tool that constitute the measuring base for the CMM machine (Figure 5). The first is the central hole-U-, which is rough milled with a $0.2 \mathrm{~mm} / \mathrm{side}$ allowance and then finished to $40 \mathrm{~mm}$. The axis of the hole -U- is the centre of the XY measuring system. The second base element is the $-\mathrm{W}$ - surface, rough milled with a $0.2 \mathrm{~mm}$ allowance, and finishing milling in the final treatments. The final base element is the lateral surface - V- relative to which one of the reference system axes is oriented. It is made in the same way as the -W- surface.

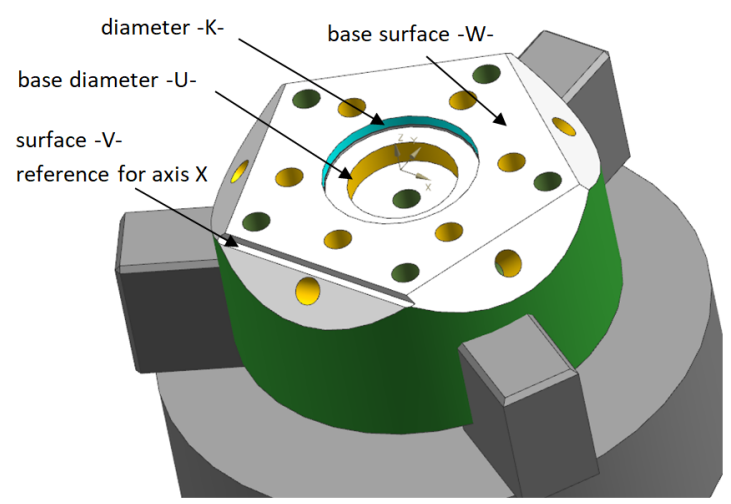

Figure 5. Test piece in the machining device with indicated base surfaces - 3D model.

\section{Test assessing the accuracy of the ma- chine tool}

The machining centre described in chapter 2 was used for testing. The machine tool purchased in 2016 was operated in a modern industrial plant in a three-shift system. It is used for machining aircraft transmission housings made of aluminium alloy castings. The machine is equipped with a cradle (fourth axis A) and a rotary table (fifth axis C).

After fixing each of the technological samples in the machine tool, the workpiece, tool and machine table were cooled for about 10 minutes with a coolant at 20 degrees Celsius. The machine tool is equipped with a coolant cooler, known as a chiller, maintaining its temperature at a given level close to the measurement temperature in the measuring laboratory.

During the control test, the machine tool rough and finish milled the test piece shown in Figure 6. The object was attached in a self-centring three-jaw chuck, which was attached to the machine table with screws. The machine tool was located in the most extreme position of the table. This was to test the geometrical accuracy of the machine in the largest possible machining space.

The surfaces of the workpiece were rough and finished milled with a milling head $\phi=100 \mathrm{~mm}$ with VHM sintered carbide inserts, with a PVD coating for aluminium machining. The cutting parameters of the milling head were respectively: rotational speed $\mathrm{S}=6000 \mathrm{rpm}$, feed speed $V_{F}=1000$ $\mathrm{mm} / \mathrm{min}$. The centric holes and the side shelf $-\mathrm{V}$ - were made with a monolithic carbide milling cutter $\phi=20 \mathrm{~mm}$ also made of sintered carbide VHM with PVD coating for aluminium machining. After rough milling, the technological allowance for the finishing machining of $0.2 \mathrm{~mm}$ was left on these surfaces. To determine the machining error for circular interpolation, the centric hole $-\mathrm{K}$ - with a diameter $\phi=56.6 \mathrm{~mm}$ was rough milled and finished. The $-\mathrm{K}$ - hole was rough milled with a finishing allowance of $0.2 \mathrm{~mm}$ on the side walls and $0.1 \mathrm{~mm}$ on the bottom of the hole. The final milling consisted of one circular interpolation path. During this transition, the cutter removed the above technology allowance. The cutting data were: $\mathrm{S}=$ $5000 \mathrm{rpm}, V_{F}=500 \mathrm{~mm} / \mathrm{min}$.

The 2.x, 3.x, 4.x group of holes, which are located on the front surface and workpiece phases, were drilled with a monolithic carbide drill with a diameter of $\phi=9.5 \mathrm{~mm}$. In finishing, these holes were expanded to a diameter of $\phi=10 \mathrm{~mm}$ using an adjustable boring bar with a VHM cemented carbide insert with a PVD coating for aluminium machining. Boring bar cutting parameters were: $\mathrm{S}=2000 \mathrm{rpm}, V_{F}=50 \mathrm{~mm} / \mathrm{min}$.

Seven pieces of the test piece were processed (Figure 7). The process was carried out on a 5-axis machining centre, described in chapter 2, in an automatic cycle without interfering with cutting parameters, tool setting and clamping method. The purpose of manufacturing the samples was to obtain the data necessary to assess the geometric accuracy of a multi-axis CNC machine. The temperature in the production hall was recorded during sample processing.

Next, in the central measuring laboratory of the plant, measurements of processed, washed and cooled technological sam- 


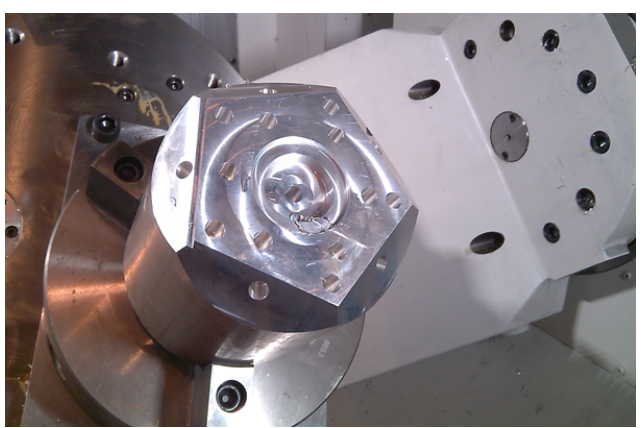

Figure 6. Test piece in the machine tool after mechanical processing.

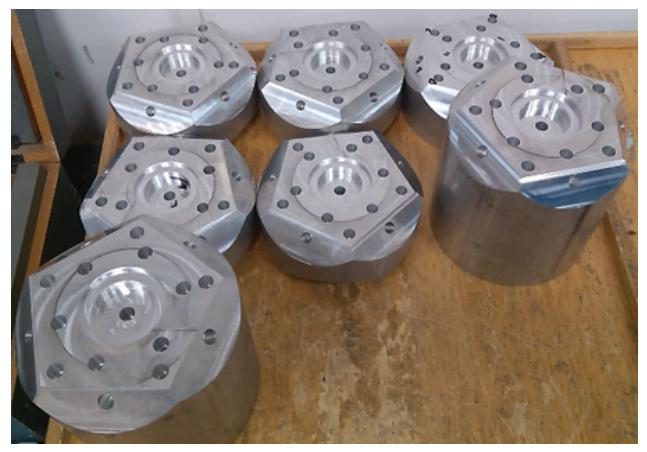

Figure 7. Processed test pieces.

ples were carried out in accordance with the standard measuring procedure approved in the plant. These dimensional-shape characteristics are the starting point for assessing the kinematic and geometric accuracy of the machine tool. A CMM equipped with touch probe was used for the measurement, with a maximum measurement error of

$$
\delta=2 \mu m+\frac{\text { range of maesurement }[\mathrm{cm}]}{100}[\mu \mathrm{m}]
$$

In order to clearly interpret the test results, a number of assumptions have been made, the most important of which are: the material used for testing is homogeneous, and any changes in its physical or chemical properties do not affect the measurement results, - the change in ambient temperature during processing on the machine tool is negligible and does not affect the value of obtained results, - the method of fixing the workpiece has no effect on the measurement results, as the measurement bases are shaped during machining, - the method of measurement using a coordinate measuring machine is repeatable and does not imply measurement errors, - thermal conditions of processing on the machine tool and measurements of individual workpieces are similar.

It was assumed that the test piece measurement report is to indirectly certify the possibility of making bearing seats for an aircraft transmission housings with an accuracy of $30 \mu \mathrm{m}$. For this reason, the tolerance of the position of test holes on the proposed technological sample was limited to $30 \mu \mathrm{m}$. The obtained measurement results are presented in Table 1, which summarizes the maximum errors among those obtained for a given group of holes for each technological sample. Data from Table 1 are presented in Figures 8, 9 and 10.

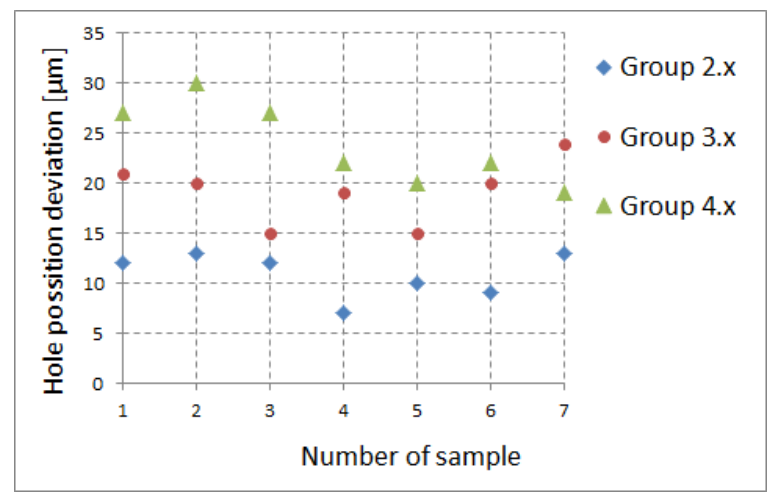

Figure 8. Maximum position errors for a group of holes for test pieces.

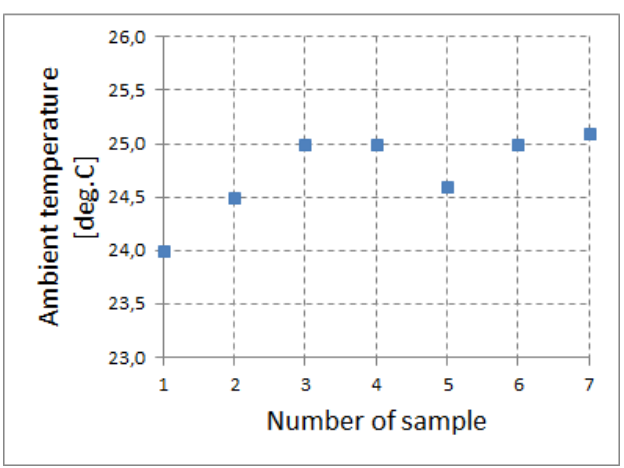

Figure 9. Temperature in the production hall during the manufacturing of test pieces.

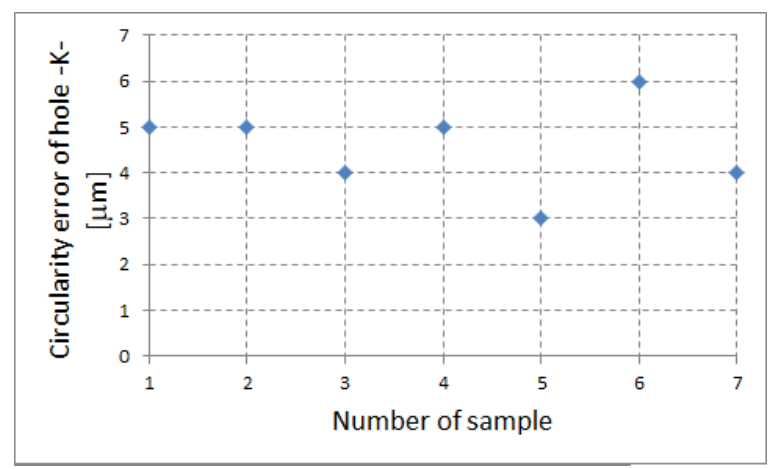

Figure 10. Circularity errors for circular interpolation of the hole -K-.

The method of manufacturing and analyzing the geometry of a test piece is an indirect method of assessing the ability of a machine to produce real workpieces. The shape of the test piece was chosen to contain all the characteristics that are most important for the manufactured aircraft transmission housings. These are: the radial and angular position of the holes and the circularity of the holes made on different planes. The quality of the hole group 2 confirms the accuracy of the housing bearing seats using the $\mathrm{X}$ axis and $\mathrm{Y}$ axis movement. The quality of the hole group 3 confirms the accuracy of the holes evenly distributed on the flange of housing, and the accuracy of their 
Table 1. Data from measurement reports of test pieces

\begin{tabular}{|c|c|c|c|c|c|}
\hline Test Piece & \multicolumn{2}{|c|}{ Max. Pos. Err. of the Holes $[\mu \mathrm{m}]$} & Max. Hole Circular. Err.-U- $[\mu \mathrm{m}]$ & Temp. in the production hall [deg. C] \\
\hline 1 & group 2.x & group 3.x & group 4.x & & 24.0 \\
2 & 12 & 21 & 27 & 5 & 24.5 \\
3 & 13 & 20 & 30 & 5 & 25.0 \\
4 & 12 & 15 & 27 & 4 & 25.0 \\
5 & 19 & 19 & 22 & 5 & 24.6 \\
6 & 10 & 15 & 20 & 3 & 25.0 \\
7 & 13 & 20 & 22 & 6 & 25.1 \\
\hline
\end{tabular}

angular position depends on the accuracy of positioning the $\mathrm{C}$ axis (divider). The quality of the hole group 4 confirms the accuracy of the holes that require a combination of movements of all machine axes. This applies to performing, without changing the mounting, such holes in the housing whose axes are not parallel, e.g. in the case of bevel gears. It must be taken into account that the test piece is adapted to the selected type of manufactured workpieces.

The measurements of the test piece show that: - the maximum position error of the 2.x group holes is $13 \mu \mathrm{m}$, - the maximum position error of group 3.x holes is $24 \mu \mathrm{m}$,

- the maximum position error of the 4.x group holes is $30 \mu \mathrm{m}$, - the maximum circularity error of the -U- hole is $6 \mu \mathrm{m}$.

The obtained errors meet the assumptions as to the accuracy placed on aircraft transmission housings, which are to be produced using the tested machine tool.

\section{Conclusions}

The finishing of the proposed test piece indirectly determines the accuracy of the 5-axis milling machine. The test piece has been designed to certify the possibility of obtaining machining dimensions for the target workpiece, i.e. aircraft transmission body.

The dimensional accuracy of the test piece was determined by measuring the position error of three groups of test holes made during machining of the test piece. The positioning error of these holes for the completed test piece is to indicate the position error, e.g. of bearing seats in the transmission body, the positioning error of the group of holes arranged on the planetary gear ring flange or the position error on the lateral surfaces of the aircraft transmission body. In addition, the test obtains information about the circular interpolation error in the machine $\mathrm{XY}$ plane.

The undoubted advantage of the proposed method is the development and use of an adequate test piece for testing or acceptance of the machine, giving information about the geometric accuracy of the machine tool during its operation. During tests, the material from which production workpieces will be made is processed. The test is carried out with the target cutting parameters for the given cutting tools. The test piece itself can be easily redesigned in such a way that the cutting tools used for its machining are the most critical tools from the point of view of the technological process of machining an airframe.

The cost of making the test piece is a negligible value in relation to the cost of precision airframe casting. Using the proposed method of assessing the accuracy of the machine tool minimizes the costs of poor quality during commissioning and testing of the machine on the so-called acceptance workpiece during its deployment.

The machine deployment process can therefore take place using the proposed test piece with appropriately selected tolerances for its dimensions, and after obtaining a series of compatible samples, we can proceed to accept the machine for target production workpieces, e.g. transmission housings.

The universality of this method is due to the fact that it is independent of the size of the machine's machining space, machine kinematics and also the special functions possessed by the machine; however, it gives a representation of their operation in the form of measuring sheets from the measuring laboratory. This method can also be used to study the geometric accuracy of the machine tool as a function of machine working time, ambient temperature changes, coolant temperature changes and more.

\section{REFERENCES}

[1] Z. Usop, A. A. Sarhan, N. A. Mardi, M. N. A Wahab. Measuring of positioning, circularity and static errors of a CNC Vertical Machining Centre for validating the machining accuracy, Measurement, Vol.61, 39-50.

[2] L. Zhong, Q. Bi, Y. Wang. Volumetric accuracy evaluation for five-axis machine tools by modeling spherical deviation based on double ball-bar kinematic test, International Journal of Machine Tools and Manufacture, Vol.122, 106-119.

[3] G. H. J. Florussen, H. A. M. Spaan, T. M. Spaan-Burke. Assessing the accuracy of five axis machines by comparing machine measurement data with test work piece deviations, Procedia Manufacturing, Vol.6, 25-32.

[4] G. H. J. Florussen, H. A. M. Spaan, T. M. Spaan-Burke. Verifying the accuracy of five-axis machine tool focused on kinematic ISO tests using a torus-shaped test work piece, Procedia Manufacturing, Vol.14, 58-65.

[5] R. Wolny. Evaluation of accuracy of 5-axis CNC milling machine on the basis of test piece machining, Annals of DAAAM \& Proceedings, Vol.29, 164-168. 
[6] M.Gebhardt, W. Knapp, K.Wegener. 5-Axis Test-Piece Influence of Machining Position, The Proceedings of MTTRF 2012 Annual Meeting, 299-304

[7] S. Ibaraki, M. Sawada, A. Matsubara, T. Matsushita. Machining tests to identify kinematic errors on five-axis machine tools, Precision Engineering, Vol.34, No.3, 387-398

[8] H. Takeshima, Y. Ihara. Finished Test Piece Example for Five-axis Machining Centers, The 5th Int. Conf. on Leading Edge Manufacturing in 21st century, Osaka, Japan, 123-126, 2009.

[9] S. Bossoni, W. Knapp, K. Wegener. Test piece for 5-axis machining centers, The Proceedings of MTTRF 2009 Annual Meeting.

[10] S. P. Radzevich. Dudley's handbook of practical gear design and manufacture, CRC Press, Boca Raton, 2016.
[11] G. Bomba, P. Gierlak. Dimensional Control of Aircraft Transmission Bodies Using CNC Machines and Neuro-Fuzzy Systems, Applied Sciences, Vol.9, No.19, 4094.

[12] B. Yang, G. Zhang, Y. Ran, H. Yu. Kinematic modeling and machining precision analysis of multi-axis CNC machine tools based on screw theory. Mechanism and Machine Theory, Vol.140, 538-552.

[13] ISO/DIS 10791-7. Test conditions for machining centers - Part 7: Accuracy of a finished test piece, Document ISO/TC 39/SC 2, 2012-02-14.

[14] Renishaw: Laser Measurment System XL-80, XL-80 Laser System Brochure. 